\title{
Extracellular Hippocampal Acetylcholine Level Controls Amygdala Function and Promotes Adaptive Conditioned Emotional Response
}

\author{
Ludovic Calandreau, ${ }^{1}$ Pierre Trifilieff, ${ }^{1}$ Nicole Mons, ${ }^{1}$ Laurence Costes,,${ }^{1,2}$ Marc Marien, ${ }^{3}$ Aline Marighetto, ${ }^{1}$ \\ Jacques Micheau, ${ }^{1}$ Robert Jaffard, ${ }^{1}$ and Aline Desmedt ${ }^{1}$ \\ ${ }^{1}$ Centre National de la Recherche Scientifique, Unité Mixte de Recherche 5106, Laboratoire de Neurosciences Cognitives, 33405 Talence, France, ${ }^{2}$ Institut \\ National de la Recherche Agronomique, Unité Mixte de Recherche 1244, Institut François Magendie, 33077 Bordeaux cedex, France, and ${ }^{3}$ Centre de \\ Recherche Pierre Fabre, Division de Neurobiologie I, 81106 Castres, France
}

\begin{abstract}
Ample data indicate that tone and contextual fear conditioning differentially require the amygdala and the hippocampus. However, mechanisms subserving the adaptive selection among environmental stimuli (discrete tone vs context) of those that best predict an aversive event are still elusive. Because the hippocampal cholinergic neurotransmission is thought to play a critical role in the coordination between different memory systems leading to the selection of appropriate behavioral strategies, we hypothesized that this cholinergic signal may control the competing acquisition of amygdala-mediated tone and contextual conditioning. Using pavlovian fear conditioning in mice, we first show a higher level of hippocampal acetylcholine release and a specific pattern of extracellular signalregulated kinase 1/2 (ERK1/2) activation within the lateral (LA) and basolateral (BLA) amygdala under conditions in which the context is a better predictor than a discrete tone stimulus. Second, we demonstrate that levels of hippocampal cholinergic neurotransmission are causally related to the patterns of ERK1/2 activation in amygdala nuclei and actually determine the selection among the context or the simple tone the stimulus that best predicts the aversive event. Specifically, decreasing the hippocampal cholinergic signal not only impaired contextual conditioning but also mimicked conditioning to the discrete tone, both in terms of the behavioral outcome and the LA/BLA ERK1/2 activation pattern. Conversely, increasing this cholinergic signal not only disrupted tone conditioning but also promoted contextual fear conditioning. Hence, these findings highlight that hippocampal cholinergic neurotransmission controls amygdala function, thereby leading to the selection of relevant emotional information.
\end{abstract}

Key words: acetylcholine; amygdala; ERK; fear; hippocampus; pavlovian conditioning

\section{Introduction}

In classical fear conditioning, subjects adaptively select among environmental stimuli those that predict an aversive event (Fendt and Fanselow, 1999; LeDoux, 2000; Yaniv et al., 2004). When a discrete conditioned stimulus (CS) (a tone) is systematically paired with the unconditional stimulus (US) (a footshock), subjects process this discrete CS as the main predictor and consign the less predictive contextual cues to the background. In contrast, when the CS has no or low predictive value (e.g., CS-US unpairing), contextual cues are selected as valid predictors (Rescorla and Wagner, 1972; Winocur et al., 1987; Desmedt et al., 1998, 1999). Although neural bases of tone and contextual fear conditioning have been extensively studied, mechanisms that specifically subserve the balance between a prevalent simple CS and contextual conditioning are still elusive.

Received Feb. 6, 2006; revised Nov. 27, 2006; accepted Nov. 28, 2006

This work was supported by the Centre National de la Recherche Scientifique. P.T. was supported by the Fondation Jérôme Lejeune. We are grateful to B. K. Yee for helpful comments on this manuscript.

Correspondence should be addressed to Dr. Aline Desmedt, Laboratoire de Neurosciences Cognitives, Avenue des Facultés, 33405 Talence, France. E-mail: a.desmedt@Inc.u-bordeaux1.fr

DOI:10.1523/JNEUROSCI.3713-06.2006

Copyright $\odot 2006$ Society for Neuroscience $\quad$ 0270-6474/06/2613556- $\bullet \$ 15.00 / 0$
We demonstrated recently that, in acquisition, the selection of either the discrete CS or the context as best predictor for the US differentially required the lateral (LA) and basolateral (BLA) nuclei of the amygdala (Calandreau et al., 2005). Nevertheless, the hippocampus is also differentially required for fear conditioning depending on the predictive value of the discrete CS (Marlin, 1981; Phillips and LeDoux, 1994; Desmedt et al., 2003). In addition, clinical studies indicate that having a hippocampaldependent episodic representation of the predictive value of CSs influences amygdala-based memories (Phelps et al., 2001; Oschner et al., 2002; Schaefer et al., 2002). These data, thus, suggest that the hippocampus could specifically influence the amygdalar function, thereby contributing to the selection of the most relevant information. However, such hippocampal influence in amygdala-based emotional learning remains essentially unknown (Phelps, 2004).

The hippocampal cholinergic neurotransmission is involved in CS processing (Wilkinson et al., 1995; Baxter et al., 1997; Gale et al., 2001; Wallenstein and Wago, 2001; Rogers and Kesner, 2004) and, importantly, is thought to play a critical role in the coordination between different neural memory systems, leading to the selection of appropriate behavioral strategies (Marighetto 
et al., 1993; Gold, 2003; Parent and Baxter, 2004). We thus hypothesized that the hippocampal cholinergic signal may control the competing acquisition of amygdala-mediated CS-US and context-US associations, which underlies adaptive emotional behaviors.

First, with in vivo microdialysis, we observed a higher hippocampal acetylcholine $(\mathrm{ACh})$ release when the context is a better predictor of shock US than the simple tone CS. Second, immunochemistry of extracellular signal-regulated kinase $1 / 2$ (ERK1/2) phosphorylation, a critical molecular device for fear conditioning (Atkins et al., 1998; Schafe et al., 2000; Shalin et al., 2004; Trifilieff et al., 2006), reveals that distinct patterns of ERK1/2 activation are observed within the LA and the BLA depending on whether the simple CS or the context is the valid predictor. Third, increasing the hippocampal cholinergic signal replaces the use of the simple tone CS by that of the context as valid predictor, thereby mimicking a predominant contextual conditioning regarding both the behavioral outcome and the LA/ BLA ERK $1 / 2$ activation pattern. In contrast, decreasing this signal mimics a predominant simple tone CS conditioning. Hence, this study reveals that hippocampal cholinergic neurotransmission controls the balance between amygdala-based contextual and simple CS conditioning.

\section{Materials and Methods}

Subjects. The experiments were conducted on naive adult (4-6 month old) male mice (C57BL/6 JI Co; Charles River Laboratories, Arbresle, France) weighing $27-32 \mathrm{~g}$. They were housed individually $7 \mathrm{~d}$ before all experiments and maintained in an animal room $\left(23^{\circ} \mathrm{C}\right)$ with a $12 \mathrm{~h}$ light/dark cycle and with ad libitum access to food and water. All of the experiments were conducted in strict compliance with current European conventions and institutional regulations.

Surgical procedure. Mice were anesthetized with ketamine and xylazine (Bayer, Wuppertal, Germany) ( $8 \mathrm{ml} / \mathrm{kg}$ body weight, i.p.) and secured in a David Kopf Instruments (Tujunga, CA) stereotaxic apparatus. For the microdialysis experiment, a guide cannulas (CMA/7; CMA Microdialysis, Solna, Sweden) was implanted just above the hippocampus [anteroposterior (A/P), $-2800 \mu \mathrm{m}$; mediolateral (M/L), $-2800 \mu \mathrm{m}$; dorsoventral $(\mathrm{D} / \mathrm{V}), 1500 \mu \mathrm{m}$; relative to dura and bregma] according to Franklin and Paxinos (1997). For intrahippocampal infusions, stainless-steel guide cannulas (26 gauge, $8 \mathrm{~mm}$ in length) were implanted bilaterally 1 $\mathrm{mm}$ above the dorsal hippocampus (A/P, $-2000 \mu \mathrm{m} ; \mathrm{M} / \mathrm{L}, \pm 1300 \mu \mathrm{m}$; $\mathrm{D} / \mathrm{V}, 1000 \mu \mathrm{m})$. In all experiments, guides were permanently fixed to the skull with dental cement and two jewel screws. Guides were obturated by appropriate stylets until behavioral manipulations. After surgery, mice were allowed to recover for at least $8 \mathrm{~d}$.

Microdialysis procedure. Twenty-four hours before fear conditioning, a microdialysis probe (CMA/7; CMA Microdialysis) filled with a Ringer's solution [in mM: $145 \mathrm{NaCl}, 3 \mathrm{KCl}, 1.3 \mathrm{CaCl}_{2}, 1 \mathrm{MgCl}_{2}$, and 1.0 aqueous phosphate buffer ( $\mathrm{PB}), \mathrm{pH} 7.4$ ] containing $0.5 \mu \mathrm{M}$ neostigmine bromide (reversible cholinesterase inhibitor; Sigma, St. Louis, MO) was inserted into the guide cannulas. Neostigmine was used because previous studies showed that, in contrast to microdialysis experiments performed in cortical regions, experiments conducted in the hippocampus required inclusion of an acetylcholinesterase inhibitor in the perfusate to observe an increase in extracellular ACh levels during behavioral training (Chang et al., 2006). Moreover, although absolute ACh levels increased with neostigmine concentrations ( $10 \mathrm{~nm}$ vs $100 \mathrm{~nm}$ vs $1 \mu \mathrm{M}$ ), the relative effect of training (compared with baseline) remained stable (Moor et al., 1998; Chang et al., 2006). On the conditioning day, the dialysis probe was connected to a microliter syringe pump (CMA/100; CMA Microdialysis) and perfused with the Ringer's solution at a flow rate of $1.0 \mu \mathrm{l} / \mathrm{min}$. After a $3 \mathrm{~h}$ equilibration period, four dialysate samples $(15 \mu \mathrm{l})$ were collected every $15 \mathrm{~min}$ for baseline measurement of endogenous ACh levels. During this period, animals were maintained in their home cage. Then, mice were transferred into the conditioning chamber without disconnecting or interrupting the perfusion and were submitted to either a pairing or an unpairing tone-shock conditioning procedure (see behavioral procedure). Afterward, animals were replaced in their home cage. After collection of a total of 16 dialysate samples, mice were disconnected from the perfusion system and returned to the animal room. All collected samples were immediately frozen and stored at $-80^{\circ} \mathrm{C}$ until assay.

ACh assay. ACh in samples was assayed by HPLC with electrochemical detection in conjunction with an enzyme reactor. ACh and choline were separated on a reversed-phase column pretreated with lauryl sulfate. A post column enzymatic reactor containing acetylcholinesterase and choline oxidase (both covalently bonded to glutaraldehyde-activated Lichrosorb NH2) converted ACh to choline and choline to hydrogen peroxide $\left(\mathrm{H}_{2} \mathrm{O}_{2}\right) . \mathrm{H}_{2} \mathrm{O}_{2}$ was detected by an electrochemical detector with a platinum electrode (Coulochem; ESA, Chelmsford, MA) set at $350 \mathrm{mV}$ versus $\mathrm{Ag} / \mathrm{AgCl}$ reference electrode. The mobile phase consisted of $0.1 \mathrm{M}$ aqueous potassium phosphate buffer, $\mathrm{pH} 8.0$, containing $2 \mathrm{~mm}$ tetramethylammonium hydroxide and $0.2 \mathrm{~mm}$ disodium EDTA acid, and was delivered by a pump at a flow rate of $0.7 \mathrm{ml} / \mathrm{min}$ (model 515; Waters, Milford, MA). The sensitivity of the system was $10 \mathrm{fmol}$. Chromatogram acquisition time was $4-5$ min.

To neutralize possible interindividual variability and optimize the detection of changes attributable to fine differences between the two behavioral procedures (see below), biochemical data are presented as relative changes (percentage from baseline) from each animal's average baseline concentration. This baseline is defined as the average of the four values preceding the conditioning. Nevertheless, because this data presentation can influence interpretation when basal values are somewhat heterogeneous, an analysis has also been conducted on the absolute, rather than the relative, changes from the averaged baseline value using a difference $(\delta)$ rather than a percentage.

Intrahippocampal infusions. For infusions, the stylets normally obtruding the guide cannulas were removed. Stainless-steel cannulas (32 gauge, $9 \mathrm{~mm}$ ) attached to $1 \mu \mathrm{l}$ Hamilton syringes (PolyLabo, Strasbourg, France) with polyethylene catheter tubing were inserted through the guide cannulas. The syringes were fixed in a constant rate infusion pump. Each mouse was given bilateral infusions $(0.2 \mu \mathrm{l})$ of normal saline (SAL) (0.9\%), scopolamine hydrobromide (SCOP) (50 $\mu \mathrm{g} / \mu \mathrm{l}$; Sigma), or physostigmine (PHY) $(0.1 \mu \mathrm{g} / \mu \mathrm{l}$; Sigma) into the dorsal hippocampus. Injections were delivered $15 \mathrm{~min}$ before the acquisition of fear conditioning (see behavioral procedure). The cannulas were left in place for an additional 3 min before removal to allow diffusion of the drug away from the cannulas tips (Desmedt et al., 1999; Calandreau et al., 2005). Scopolamine and physostigmine were dissolved in $0.9 \%$ saline solution. The dose of scopolamine has been selected on the basis of previous studies (Gale et al., 2001; Wallenstein and Wago, 2001) reporting specific effects of intrahippocampal infusions of 20,50 , or $100 \mu \mathrm{g} / \mu \mathrm{l}$ scopolamine on different learning tasks. The dose of physostigmine was selected on the basis of a pilot study, using $0.1,1$, or $10 \mu \mathrm{g} / \mu \mathrm{l}$ physostigmine, in which the criteria for selection were the absence of drug-induced major changes in the general behavioral state of animals.

Dose-response analyses. Additional groups of mice were submitted to the same intrahippocampal infusion procedure but received either saline or 20,50 , or $100 \mu \mathrm{g} / \mu \mathrm{l}$ scopolamine infusions $(0.2 \mu \mathrm{l} / \mathrm{side}) 15 \mathrm{~min}$ before the unpairing conditioning procedure (see behavioral procedure). A second cohort of mice was submitted to either saline or $0.02,0.1$, or $1 \mu \mathrm{g} / \mu \mathrm{l}$ physostigmine infusions $(0.2 \mu \mathrm{l} / \mathrm{side}) 15 \mathrm{~min}$ before the pairing conditioning procedure.

Fear conditioning procedures. Classical fear conditioning took place in a Plexiglas chamber $(30 \times 24 \times 22 \mathrm{~cm})$, giving access to the different visual-spatial cues in the experimental room. The floor of this conditioning chamber consisted of stainless-steel rods ( $2 \mathrm{~mm}$ diameter), spaced 5 $\mathrm{mm}$ apart and connected to a shock generator (Imetronic, Talence, France). The four sides of the chamber and the rods of the floor were cleaned with $70 \%$ ethanol before each trial. For acquisition, half of the animals were given two explicit pairings of the tone CS $(63 \mathrm{~dB}, 1 \mathrm{kHz}$, $15 \mathrm{~s})$ and a footshock US $(0.7 \mathrm{~mA}, 50 \mathrm{~Hz}, 3 \mathrm{~s})$. Specifically, each animal was placed in the conditioning chamber for $4 \mathrm{~min}$; $100 \mathrm{~s}$ after being placed into the chamber, a tone was presented and was immediately followed by a footshock. Sixty seconds later, the same tone-shock pairing 
was presented. After an additional delay of $40 \mathrm{~s}$, each mouse was removed from the conditioning chamber and replaced in its home cage. In this training condition, the prevalent association is the elemental CS-US association, which consigns the conditioning context to the background. The other half of the subjects was trained under the unpairing toneshock procedure, which differed from the previous training condition in that the two shocks and the two tones were pseudorandomly distributed. Specifically, $100 \mathrm{~s}$ after being placed into the chamber, animals received a footshock, and then, after a $20 \mathrm{~s}$ delay, a tone was presented; finally, after a $30 \mathrm{~s}$ delay, the same tone and the same shock spaced out $30 \mathrm{~s}$ apart were presented, and each animal was replaced in its home cage after a final delay of $20 \mathrm{~s}$. This explicitly unpaired arrangement of tone and shock is known to enable the contextual cues to be processed as the primary stimuli to enter into association with the US (i.e., context in foreground) (Desmedt et al., 1999; Calandreau et al., 2005).

Twenty-four hours later, while animals were drug free, they were tested for freezing behavior (measured second-by-second), used as an index of conditioned fear and defined as a lack of all movement, except for respiratory-related movements (Blanchard and Blanchard, 1969). First, mice were submitted to the auditory cue test in which they were maintained in their home cage and three successive recording sessions of behavioral responses were performed: one before (first $2 \mathrm{~min}$ ), one during (next $2 \mathrm{~min}$ ), and one after (2 last $\mathrm{min}$ ) tone presentation. Two hours later, mice were submitted to the context test: they were reexposed for 4 min to the conditioning chamber. Animals were continuously videotaped for off-line scoring of freezing.

Assessment of the specificity of the conditioned fear response to the tone CS. Additional groups of mice submitted, as above detailed, to intrahippocampal saline infusions and to the tone CS-US pairing procedure, were subsequently tested for freezing behavior to the tone CS (auditory cue test, 24 or $48 \mathrm{~h}$ later) and to a discrete neutral new tone (white noise) ( 48 or $24 \mathrm{~h}$ later) in a counterbalanced manner. The same behavioral testing procedure was performed in an additional group of scopolamineinfused animals submitted to a CS-US unpairing procedure. The specific increase in conditioned freezing behavior to the tone CS in both the saline-infused paired group and the scopolamine-infused unpaired group was thus assessed in a discrimination task by measuring the conditioned fear to the tone CS compared with the fear expressed to the white noise.

In addition, two additional control groups of saline-infused mice were submitted to either a white noise-US pairing or unpairing procedure to assess the ability of animals to specifically process this discrete white noise as a predictive CS when it is paired with the footshock US.

Assessment of locomotor activity. To assess to what extent drug infusion-dependent changes in freezing behavior could be attributable to changes in locomotor behavior, the activity of mice was assessed in the first behavioral test, $24 \mathrm{~h}$ after conditioning while animals were drug free. The number of ambulatory crossovers, which are used as a relevant index of animal activity (Gale et al., 2001), were measured during 1 min period before tone delivery while mice were placed in the neutral context (home cage used for the auditory cue test). A crossover was defined as the animal's hindpaws crossing the midline of the observation chamber.

Histology. After completion of behavioral evaluations, animals were given an overdose of sodium thiopental $(120 \mathrm{mg} / \mathrm{kg})$ and transcardially perfused with physiological saline, followed by $10 \%$ buffered Formalin. Brains were postfixed in Formalin-saccharose 30\% solution for 1 week, frozen, cut coronally on a sliding microtome into $60 \mu \mathrm{m}$ sections that were mounted on gelatin-coated glass slides, and stained with thionine to evaluate the cannula placements.

Immunohistochemistry. Thirty mice were anesthetized $15 \mathrm{~min}$ after the fear conditioning session by overdose of sodium thiopental $(120 \mathrm{mg} / \mathrm{kg})$ and perfused intracardiacally with $100 \mathrm{ml}$ of $4 \%$ paraformaldehyde in 0.1 $\mathrm{M} \mathrm{Na}_{2} \mathrm{HPO}_{4} / \mathrm{NaH}_{2} \mathrm{PO}_{4}$ buffer, $\mathrm{pH} 7.5,4^{\circ} \mathrm{C}$. Brains were removed, postfixed for $12 \mathrm{~h}$ in the same fixative solution described above, and then sectioned using a Vibratome (Leica, Nussloch, Germany). Sections were immediately processed for immunohistochemistry. Specifically, after four rinses (15 min each) in Tris-buffered saline (TBS/NaF) (0.1 M Tris and $0.5 \mathrm{M} \mathrm{NaCl}, 0.5 \mathrm{~g} / 240 \mathrm{ml} \mathrm{NaF}, \mathrm{pH} 7.5$ ), sections were incubated for 30 min in a TBS/ $\mathrm{NaF}$ solution containing $0.5 \% \mathrm{H}_{2} \mathrm{O}_{2}$. After an additional four rinses in $\mathrm{TBS} / \mathrm{NaF}$, sections were incubated at $4^{\circ} \mathrm{C}$, first for $1 \mathrm{~h}$ in a TBS/NaF- $0.2 \%$ Triton $\mathrm{X}-100-3 \%$ bovine serum (BSA) solution and, second, for $48 \mathrm{~h}$ in the solution containing the primary antibody anti phospho-ERK1/2 [anti-phospho $\mathrm{Thr}^{202}-\mathrm{Tyr}^{204}$, rabbit polyclonal antibody, 1:500 (Cell Signaling Technology, Beverly, MA) in TBS/NaF-0.2\% Triton X-100-3\% BSA]. After this incubation phase, sections were rinsed in TBS and incubated for $2 \mathrm{~h}$ with the secondary biotinylated antibody [anti-rabbit IgG, 1:2000 (Jackson ImmunoResearch, West Grove, PA) in TBS]. They were afterward rinsed and incubated at room temperature for $2 \mathrm{~h}$ in avidin-biotin complex solution ( $\mathrm{ABC}$ solution; Vector Laboratories, Burlingame, CA) in TBS. Finally, sections were rinsed in TBS and Tris buffer, and the peroxidase reaction end product was visualized in $0.05 \mathrm{~m}$ Tris buffer, $\mathrm{pH}$ 7.6, containing diaminobenzidine tetrahydrochloride $(0.025 \%), 0.03 \% \mathrm{H}_{2} \mathrm{O}_{2}$, and $5 \%$ nickel ammonium sulfate for $10 \mathrm{~min}$. Immunolabeled sections were washed in $\mathrm{PB}$, mounted onto gelatin-coated glass slides, and dehydrated through an alcohol to toluene series before examination by light microscopy. A video camera (DXC-950P; Sony, Tokyo, Japan) attached to a microscope (BX 50; Olympus Optical, Tokyo, Japan) and connected to an analysis software (Visiolab 2000, version 4.50; Biocom, San Diego, CA) was used for labeled cells quantification. For all brain regions, six measurements (three per hemisphere) were made from three different sections per animal and averaged. Quantifications were performed at $10 \times$ magnification. Sections from dentate gyrus (DG), CA3, and CA1 areas quantified in the dorsal hippocampus were between bregma $-2 \mathrm{~mm}$ and bregma $-2.4 \mathrm{~mm}$. Sections from these areas quantified in the ventral hippocampus were between bregma -2.9 and bregma $-3.3 \mathrm{~mm}$ (Franklin and Paxinos, 1997). DG granular cell layer and CA1 and CA3 pyramidal layers were targeted. Sections from BLA were between bregma $-1.2 \mathrm{~mm}$ and bregma $-1.6 \mathrm{~mm}$, and sections from LA were between bregma -1.4 and bregma -2 . The computer automatically counted all positive targets in the regions of interest excluding noncellular irregularities in the background staining. Results were expressed as number of phosphorylated ERK1/2 (p-ERK1/2)-positive cells per square millimeter for each region. At all stages, the experimenter was blind to the experimental groupings.

Data analysis. Statistical analyses were performed using ANOVA, followed by $t$ test for pairwise comparisons when appropriate (Statview; SAS Institute, Cary, NC).

\section{Results}

\section{Hippocampal ACh release depends on the conditioning procedure}

To show the differential recruitment of the hippocampal cholinergic system in fear conditioning as a function of the informative value of the CS, we compared the time course of the ACh release in the hippocampus between two conditioning procedures (i.e., CS-US pairing and CS-US unpairing) using in vivo microdialysis.

Basal extracellular levels of ACh (raw values) measured before acquisition (first four samples) were similar between the two groups $\left(F_{(1,9)}=0.499, p>0.05\right)$ and did not vary significantly across time $\left(F_{(3,27)}=1.76, p>0.05\right)$. The statistical analysis conducted on percentage from baseline revealed that conditioning induced an increase in ACh release $\left(F_{(6,54)}=14.81, p<\right.$ 0.0001 ) that lasted for $\sim 30 \mathrm{~min}$ after conditioning (Fig. $1 A$ ). This increase was significantly higher in the unpaired group than in the paired group (time $\times$ conditioning, $F_{(6,54)}=2.51, p=0.032$ ). Specifically, during the first $30 \mathrm{~min}$ after conditioning, ACh levels were higher in the unpairing compared with the pairing condition $\left(F_{(1,9)}=5.78, p=0.039\right)$. The same analysis conducted on absolute, rather than relative, values (Fig. $1 B$ ) also confirmed this conditioning effect $\left(F_{(1,9)}=8.48, p=0.017\right)$.

It is important to note that the use of neostigmine in the perfusate can hardly explain the differential training-dependent ACh release observed. First, previous studies have shown that, although the ACh levels increased with neostigmine concentra- 

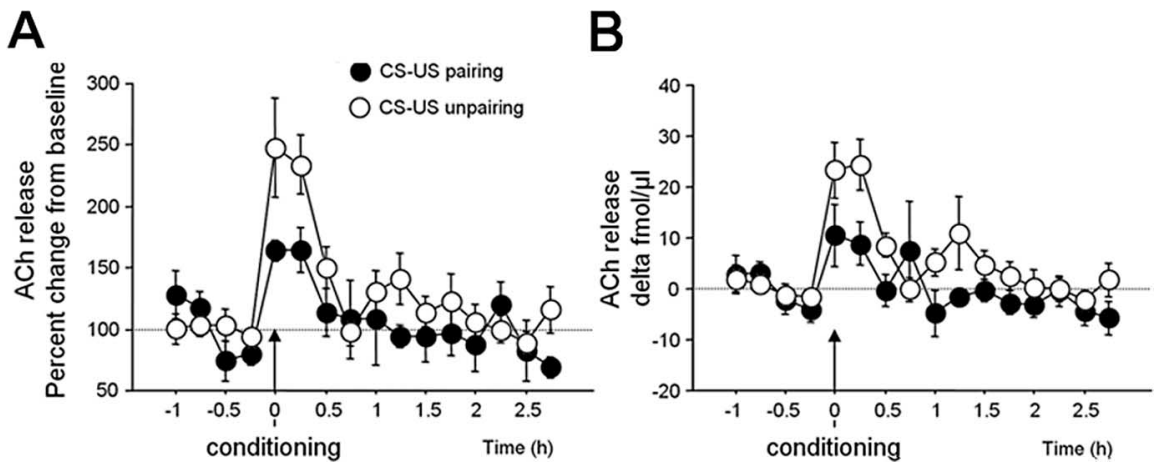

Figure 1. Time course of $A C h$ release in the hippocampus as a function of the conditioning procedure. Extracellular ACh variation is expressed in percentage of baseline levels $(\boldsymbol{A})$ and in $\delta$ femtomoles per microliter $(\boldsymbol{B} ;$ mean \pm SEM) in animals submitted to either a CS-US pairing $(n=5)$ or CS-US unpairing procedure $(n=6)$.

tions (10 $\mathrm{nM}$ vs $100 \mathrm{nM}$ vs $1 \mu \mathrm{M}$ ), the relative effect of training (compared with baseline) remained stable (Moor et al., 1998; Chang et al., 2006). This indicates that the training effect on ACh release overcomes that of neostigmine infusions. Second, while using the same neostigmine concentration $(0.5 \mu \mathrm{M})$ in both groups, the present experiment clearly shows a differential ACh release in the hippocampus as a function of the training procedure used (CS-US unpairing vs pairing).

\section{Hippocampal ACh and simple tone fear conditioning}

The previous experiment indicates that conditioning induces less ACh release in the hippocampus when the tone CS is fully predictive of the occurrence of the US (pairing procedure) than when it is nonpredictive (unpairing procedure). The following experiment was aimed at determining whether the level of hippocampal cholinergic neurotransmission is causally linked with the magnitude of conditioning to the tone CS. For this purpose, the effects of pharmacologically induced decrease or increase in this cholinergic neurotransmission on fear conditioning to the discrete tone were assessed. Infusions into the dorsal hippocampus of muscarinic antagonist scopolamine or acetylcholinesterase inhibitor physostigmine were performed 15 min before training with either the CS-US pairing or unpairing procedure. Effects of these intrahippocampal infusions were assessed on conditioned freezing to the tone measured $24 \mathrm{~h}$ later. As expected, saline-infused mice displayed much more freezing specific to tone presentation when trained with the pairing than with the unpairing procedure $\left(F_{(1,19)}=34.91 ; p<0.0001\right)$ (Fig. $\left.2 A\right)$. This training-dependent effect was abolished in the scopolamine (conditioning $\times$ treatment, $F_{(1,36)}=8.506, p=0.006$; no conditioning effect in SCOP, $\left.F_{(1,17)}=0.32, p>0.05\right)$ and physostigmine-infused groups (conditioning $\times$ treatment, $F_{(1,36)}$ $=5.802, p=0.021$; no conditioning effect in $\mathrm{PHY}, F_{(1,17)}=0.60$, $p>0.05)$. Specifically, despite being trained with the pairing procedure, physostigmine-infused mice displayed no conditioning to the tone (PHY vs SAL, $F_{(1,18)}=18.96, p=0.0004$ ). In contrast, scopolamine-infused mice displayed significant conditioning to the tone even when trained without any explicit tone CS-US pairing (SCOP vs SAL, $F_{(1,17)}=15.91, p=0.0009$ ).

These results cannot be attributable to differences in posttone freezing or in baseline freezing values. Indeed, a statistical analysis conducted on post-tone freezing values revealed no significant effect of the treatment $\left(F_{(2,53)}=0.31, p>0.05\right)$, whatever the conditioning procedure used (treatment $\times$ conditioning, $\left.F_{(2,53)}=0.30, p>0.05\right)$ and no significant effect of conditioning $\left(F_{(1,53)}=0.10, p>0.05\right)$. The same analysis conducted on base- line freezing values [(pre-tone + posttone values)/2] also did not reveal any significant effect of treatment $\left(F_{(2,53)}=0.71\right.$, $p>0.05)$, conditioning $\left(F_{(1,53)}=0.53\right.$, $p>0.05)$, or significant treatment $\times$ conditioning interaction $\left(F_{(2,53)}=1.59, p>\right.$ 0.05 ) (supplemental Table $1 A$, available at www.jneurosci.org as supplemental material).

\section{Hippocampal ACh and contextual fear conditioning}

The previous results show that blocking and increasing the hippocampal cholinergic neurotransmission promotes and disrupts conditioned freezing to the tone $\mathrm{CS}$, after conditioning in the unpairing and pairing procedures, respectively. Previous studies indicated that the prevalent tone CS-US association is replaced by a prevalent context-US association when diminishing the informative value of the CS (from CS-US pairing to unpairing procedure) (Rescorla and Wagner, 1972; Winocur et al., 1987; Desmedt et al., 1998, 1999; Calandreau et al., 2005). We thus next examined on the same animals whether, compared with tone fear conditioning, such cholinergic manipulation could result in opposite changes on contextual conditioning. As expected, saline-infused mice trained under the unpairing procedure (context in the foreground) displayed significantly more conditioned freezing to the context than saline-infused mice trained with the pairing procedure (context in the background) $\left(F_{(1,19)}=64.41, p<0.0001\right)$ (Fig. $2 B$ ). This training-induced difference in contextual freezing was abolished in both the scopolamine-infused (conditioning $X$ treatment, $F_{(1,36)}=56.76, p<0.0001$; no conditioning effect in SCOP, $\left.F_{(1,17)}=1.96, p>0.05\right)$ and physostigmine-infused (conditioning $\times$ treatment, $F_{(1,36)}=17.11, p=0.0002$; no conditioning effect in PHY, $\left.F_{(1,17)}=0.50, p>0.05\right)$ groups. Specifically, regardless of the training condition, scopolamine-infused mice overall displayed significantly lower levels of conditioned freezing to the context than saline-infused mice $\left(F_{(1,36)}=99.67, p<\right.$ $0.0001)$. This scopolamine-induced decrease in contextual freezing was mainly observed in the unpairing condition $\left(F_{(1,17)}=\right.$ $109,84, p<0.0001)$. In contrast, physostigmine infusions enhanced contextual freezing in the pairing condition $\left(F_{(1,18)}=\right.$ $10.02, p=0.005)$. Although physostigmine infusions reduced contextual freezing in animals trained with the unpairing procedure $\left(F_{(1,18)}=8.72, p=0.008\right)$, these levels of freezing did not significantly differ from that of physostigmine-infused mice trained with the pairing procedure.

\section{Dose-response analyses of scopolamine and physostigmine infusions}

Our previous experiments show that (1) intrahippocampal infusions of $50 \mu \mathrm{g} / \mu \mathrm{l}$ scopolamine do induce a conditioned fear to the tone CS but disrupts contextual conditioning in mice trained with the unpairing procedure and that (2) in contrast, physostigmine infusions $(0.1 \mu \mathrm{g} / \mu \mathrm{l})$ enhance contextual fear conditioning to the detriment of tone fear conditioning when mice are trained with the pairing procedure. To confirm the specific effect of each drug observed in the unpairing (SCOP) and pairing (PHY) conditions, respectively, a dose-response experiment has been conducted in animals submitted to a CS-US unpairing procedure (SAL vs SCOP, 20, 50, or $100 \mu \mathrm{g} / \mu \mathrm{l} ; 0.02 \mu \mathrm{l} /$ side) and in animals 
A

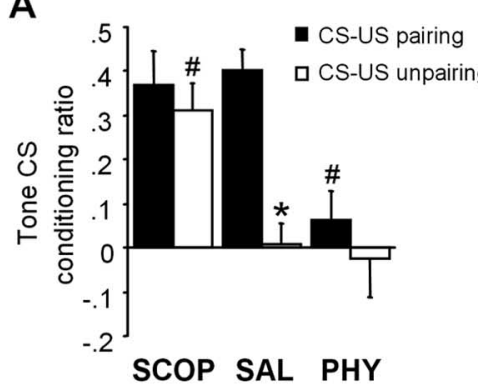

C

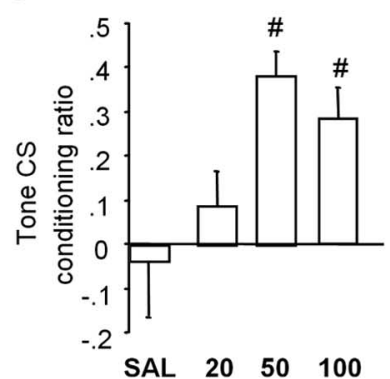

E

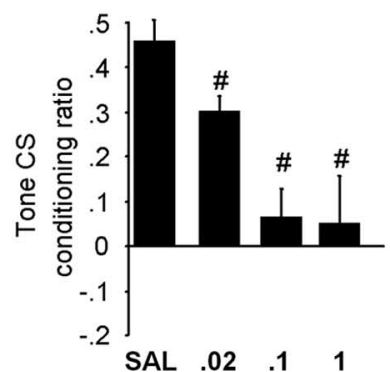

B

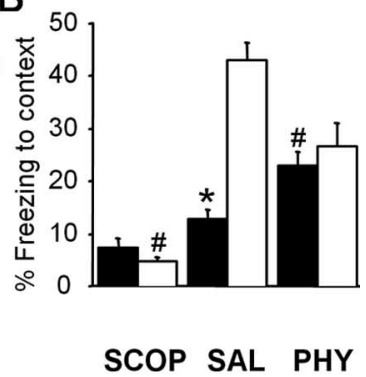

D

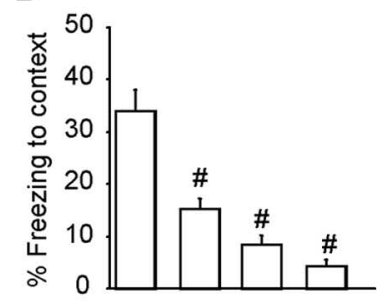

SAL $\quad 20 \quad 50 \quad 100$

$\mathbf{F}$

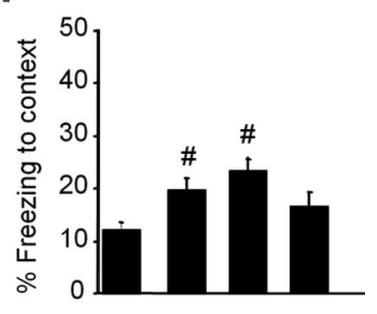

$\begin{array}{llll}\text { SAL } & .02 & .1 & 1\end{array}$

Figure 2. Effects of intrahippocampal infusions of SAL, SCOP, and PHY on cue tone and contextual fear conditioning as a function of the conditioning procedure. $A$, Auditory cue test. Conditioned response to the tone is expressed as percentage of freezing increase to the tone with respect to a baseline freezing level (i.e., pre-tone/post-tone periods mean). The ratio was calculated as follows: [\% freezing during the tone presentation - (\% pre-tone period freezing $+\%$ post-tone period freezing)/2]/[\% freezing during the tone presentation $+(\%$ pretone period freezing $+\%$ post-tone period freezing)/2]. Values of this ratio (mean $\pm \mathrm{SEM}$ ) are illustrated for mice submitted to SAL $(n=21), \operatorname{SCOP}(n=19)$, or PHY $(n=19)$ intrahippocampal infusions before either a CS-US pairing or a CS-US unpairing procedure. $\boldsymbol{B}$, Context test. Percentage of conditioned freezing (mean \pm SEM) during the 4 min reexposure period in animals submitted to SAL, SCOP, or PHY intrahippocampal infusions before either a CS-US pairing or unpairing procedure. C, Scopolamine dose effect on conditioned freezing to the tone CS (mean \pm SEM) in mice submitted to SAL $(n=7)$ or SCOP intrahippocampal infusions [20 $(n=8), 50(n=17)$, or $100 \mu \mathrm{g} / \mu \mathrm{l}(n=8)]$ before a (S-US unpairing procedure. $\boldsymbol{D}$, Scopolamine dose effect on conditioned freezing to the context (mean \pm SEM) in animals submitted to SAL or SCOP intrahippocampal infusions $(20,50$, or $100 \mu \mathrm{g} / \mu \mathrm{l})$ before a CS-US unpairing procedure. $\boldsymbol{E}$, Physostigmine dose effect on conditioned freezing to the tone CS (mean \pm SEM) in mice submitted to SAL ( $n=14)$ or PHY intrahippocampal infusions [0.02 $(n=9), 0.1(n=$ 9), or $1 \mu \mathrm{g} / \mu \mathrm{l}(n=8)]$ before a CS-US pairing procedure. $\boldsymbol{F}$, Physostigmine dose effect on conditioned freezing to the context (mean \pm SEM) in animals submitted to SAL or PHY intrahippocampal infusions $(0.02,0.1$, or $1 \mu \mathrm{g} / \mu \mathrm{l})$ before a CS-US pairing procedure. * indicates conditioning effect (CS-US pairing vs unpairing); \# indicates pharmacological effect (SAL vs SCOP or SAL vs PHY).

submitted to a pairing procedure (SAL vs PHY, 0.02, 0.1, or 1 $\mu \mathrm{g} / \mu \mathrm{l})$.

First, the effects of scopolamine infusions in the unpairing condition were dependent on the dose used whichever the behavioral test (dose effect in auditory cue test, $F_{(3,36)}=6.50, p=0.001$; in context test, $\left.F_{(3,36)}=26.40, p<0.0001\right)$. As shown in Figure

$2 C$, infusions of $20 \mu \mathrm{g} / \mu \mathrm{l}$ scopolamine had no significant effect on tone conditioning compared with saline infusions $\left(F_{(1,13)}=\right.$ $0.69, p>0.05)$, whereas infusions of both 50 and $100 \mu \mathrm{g} / \mu \mathrm{l}$ resulted in a significant increase in conditioning to the tone $\left(F_{(1,22)}=13.56, p=0.001\right.$ and $F_{(1,13)}=5.62, p=0.033$, respectively). It must be noted, however, that the $50 \mu \mathrm{g} / \mu \mathrm{l}$ infusions are the only ones to significantly enhance tone fear conditioning compared with the $20 \mu \mathrm{g} / \mu \mathrm{l}$ infusions (50 vs $20, F_{(1,23)}=10.01$, $p=0.004 ; 100$ vs $\left.20, F_{(1,14)}=3.81, p>0.05\right)$. These doseresponse effects cannot be attributable to differences in post-tone freezing or in baseline freezing values (supplemental Table $1 B$, available at www.jneurosci.org as supplemental material). Results from the context test (Fig. 2D) revealed that, although all concentrations of scopolamine reduced levels of freezing to context (all $F$ values $>17$, all $p$ values $<0.002$ ), the disrupting effect of $50 \mu \mathrm{g} / \mu \mathrm{l}$ infusions was significantly more pronounced than that produced by $20 \mu \mathrm{g} / \mu \mathrm{l}\left(50 \mathrm{vs} 20, F_{(1,23)}=5.06, p=0.034\right)$ but was not different from that produced by the highest dose (50 vs $\left.100, F_{(1,23)}=2.44, p>0.05\right)$. All in all, these results provide evidence for an optimal efficacy of $50 \mu \mathrm{g} / \mu \mathrm{l}$ scopolamine in mimicking a preferential tone fear conditioning to the detriment of contextual fear conditioning.

Second, the effects of physostigmine infusions in the pairing condition were also dependent on the dose used whichever the behavioral test (dose effect in auditory cue test, $F_{(3,36)}=9.53, p<$ 0.0001 ; in context test, $\left.F_{(3,36)}=5.05, p=0.005\right)$. As shown in Figure $2 E$, although all concentrations impaired tone fear conditioning (all $F$ values $>4.8, p$ values $<0.04$ ), the disrupting effect of $0.1 \mu \mathrm{g} / \mu \mathrm{l}$ was significantly more pronounced than that produced by $0.02 \mu \mathrm{g} / \mu \mathrm{l}\left(0.1\right.$ vs $\left.0.02, F_{(1,16)}=9.67, p=0.006\right)$ but was not different from that induced by the highest dose $(0.1$ vs 1 , $\left.F_{(1,15)}=0.014, p>0.05\right)$. Once again, these dose-response effects cannot be attributable to differences in post-tone freezing or in baseline freezing values (supplemental Table $1 C$, available at www.jneurosci.org as supplemental material). Results from the context test indicated that, although all doses tested tended to increase contextual conditioning (Fig. $2 F$ ), infusions of 0.1 and $0.02 \mu \mathrm{g} / \mu \mathrm{l}$ physostigmine were the only ones to significantly increase levels of freezing to context compared with saline infusions $\left(_{(1,21)}=15.05, p=0.0009\right.$ and $F_{(1,21)}=8.56, p=0.008$, respectively). All in all, these results provide evidence for a maximal efficacy of $0.1 \mu \mathrm{g} / \mu \mathrm{l}$ physostigmine in mimicking a preferential contextual fear conditioning to the detriment of tone fear conditioning.

\section{Specificity of the conditioned fear response to the tone CS}

To assess the extent to which the increased freezing levels to the tone CS observed in control paired and in scopolamine-infused unpaired mice were specific to the tone CS, we compared the levels of conditioned freezing to the discrete CS with the fear responses expressed to a neutral white noise. As shown in Figure $3 A$, in each group, animals displayed significantly more freezing to the tone CS than to the white noise (control paired, $F_{(1,13)}=$ 19.90, $p=0.0006$; SCOP unpaired, $\left.F_{(1,16)}=15.95, p=0.001\right)$. Because this behavioral discrimination was observed whatever the order of the tests [type of test (white noise vs tone CS test) $\times$ order (24 vs $48 \mathrm{~h}), F_{(1,12)}=0.88, p>0.05$ in control paired; $F_{(1,15)}=1.68, p>0.05$ in SCOP unpaired], results have been pooled for each group.

It must be noted that this discrimination cannot be attributable to the fact that mice cannot display freezing behavior to the white noise. Indeed, as shown in Figure 3B, among additional control mice, those submitted to a white noise-US pairing pro- 
A

CS-US pairing
- CS-US unpairing

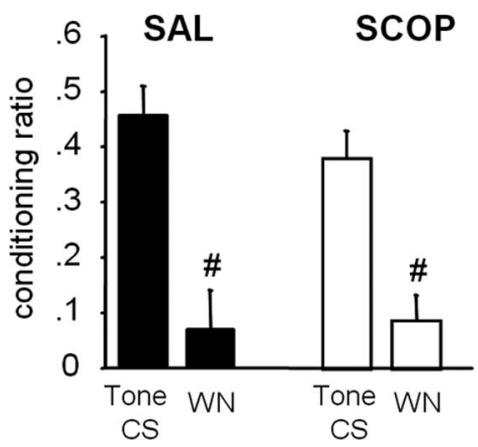

Figure 3. Specificity of the freezing response to the tone $C S$. $A$, Fear responses to the tone $C S$ and to the neutral white noise (WN) is expressed as percentage of freezing increase to the tone, or to the white noise, with respect to a baseline freezing level (i.e., pre-tone/post-tone periods mean). Values of this ratio (mean \pm SEM) are illustrated for SAL-infused mice submitted to a CS-US pairing procedure ( $n=14)$ and for SCOP-infused mice submitted to an unpairing procedure $(n=17)$. $\boldsymbol{B}$, Conditioned freezing responses to the white noise (WN) CS, expressed as percentage of freezing increase to the WN with respect to a baseline freezing level (mean \pm SEM) in SAL-infused mice submitted to a WN-US pairing $(n=5)$ or unpairing procedure $(n=$ 6). * indicates conditioning effect (CS-US pairing vs unpairing); \# indicates test effect (tone CS vs white noise).

cedure significantly displayed more conditioned fear to the white noise CS than mice submitted to an unpairing procedure (conditioning effect, $\left.F_{(1,9)}=29.76, p=0.0004\right)$. This pattern of results shows that the white noise used can actually be processed as a discrete tone CS when it is paired with the footshock US. Altogether, these results indicate that increased levels of freezing to the tone CS in control paired and SCOP-infused unpaired mice are specific to the discrete CS and cannot be explained in terms of generalized fear to other discrete auditory stimuli.

Finally, the specificity of the conditioned response to the tone CS cannot be attributable to differences in post-tone freezing or in baseline freezing levels (supplemental Table $1 D, E$, available at www.jneurosci.org as supplemental material).

\section{Locomotor activity}

Our previous experiments provide evidence for a maximal efficacy of intrahippocampal infusions of $50 \mu \mathrm{g} / \mu \mathrm{l}$ scopolamine and $0.1 \mu \mathrm{g} / \mu \mathrm{l}$ physostigmine. These effects were dependent on both the conditioning procedure and the behavioral test, suggesting that drug-induced changes in freezing behavior are unlikely to be attributable to a general alteration in locomotor activity. Nevertheless, to directly examine the question of a potential longlasting effect of drug infusions on locomotor activity, we measured the number of crossovers in mice, $24 \mathrm{~h}$ after conditioning. The measure of crossovers revealed no significant differences in levels of activity between SAL-, SCOP-, and PHY-infused mice whatever the conditioning procedure used (treatment, $F_{(2,53)}=$ $0.61, p>0.05$; treatment $\times$ conditioning, $\left.F_{(2,53)}=1, p>0.05\right)$ (Fig. 4). This supplementary analysis thus confirmed that differences in freezing levels between the different groups cannot be attributable to changes in levels of locomotor activity.

\section{ACh manipulation affects ERK1/2 activation}

Our previous analyses revealed that hippocampal cholinergic activity plays a crucial role in the processing of, and competition between, context-US and elemental (tone) CS-US associations.

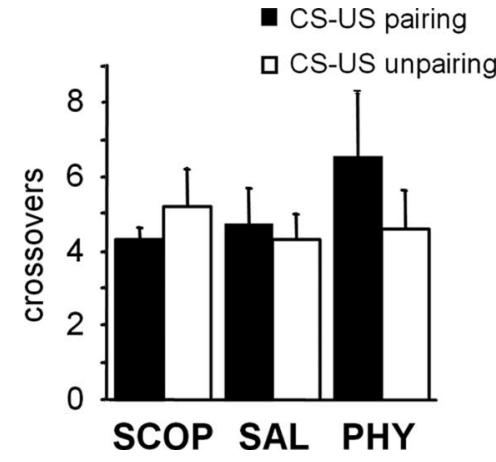

Figure 4. Locomotor activity. Number of crossovers (mean \pm SEM) during the first minute of the auditory cue test displayed by mice previously submitted to SAL, SCOP $(50 \mu \mathrm{g} / \mu \mathrm{l})$, or PHY $(0.1 \mu \mathrm{g} / \mu \mathrm{l})$ intrahippocampal infusions before either a CS-US pairing or unpairing procedure.

Increasing cholinergic transmission by physostigmine suppresses the use of the tone CS as a valid (pairing procedure) predictor for the occurrence of the US and gives more credence to the background context as a predictor. In contrast, decreasing such transmission by scopolamine tends to make the animals perceive the invalid CS (unpairing procedure) as if it was a reliable predictor for US occurrence, in the expense of the relatively more valid context. These findings suggest that intrahippocampal infusions of physostigmine and of scopolamine mimic the processing of cues by normal subjects trained under the unpairing and pairing procedure, respectively.

The following experiment was designed to determine whether, and the extent to which, intrahippocampal infusions of each drug (SCOP, $50 \mu \mathrm{g} / \mu \mathrm{l}$; PHY, $0.1 \mu \mathrm{g} / \mu \mathrm{l}$ ) could bias the functioning of the hippocampus and the amygdala in a manner consistent with our hypothesis developed above.

To this end, a separate cohort of mice was prepared as before, underwent intrahippocampal infusions, and were then conditioned as described above. They were then killed 15 min after training for examination of phosphorylation of ERK1/2. Activation of ERK1/2 was studied because it is an important molecular marker commonly used to delineate learning-dependent circuits as a function of the prevalent conditioned association encoded. First, previous studies demonstrated that p-ERK1/2 can serve in neural cells, and particularly in hippocampal neurons, as convergence site for several neurotransmitter receptor activation, including acetylcholine receptors (Rosenblum et al., 2000; Berkeley et al., 2001). Second, ERK1/2 activation has been shown to be critically required for learning-dependent plasticity within the hippocampus and the amygdala, in contextual and tone CS fear conditioning, respectively (Atkins et al., 1998; Schafe et al., 2000; Shalin et al., 2004; Revest et al., 2005; Trifilieff et al., 2006). We thus examined ERK1/2 phosphorylation to map and compare the patterns of activation of different hippocampal and amygdalar subregions as a function of the pharmacologically induced manipulation of the hippocampal cholinergic transmission.

\section{ACh manipulation affects ERK1/2 activation in} the hippocampus

p-ERK1/2 levels were assessed within the DG, CA3 (Fig. 5A), and CA1 (Fig. 5B) hippocampal subfields. Scopolamine and physostigmine produced an overall opposite effect on $\mathrm{p}$-ERK1/2 expression within the hippocampus with respect to saline. Specifically, scopolamine decreased ERK1/2 phosphorylation with a statistically significant effect in ventral $\left(F_{(1,16)}=5.72, p=0.029\right)$ and dorsal $\left(F_{(1,15)}=15.22, p=0.001\right)$ CA1. In contrast, phy- 
A CS-US pairing
$\square$ CS-US unpairing

Dorsal

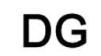

Ventral

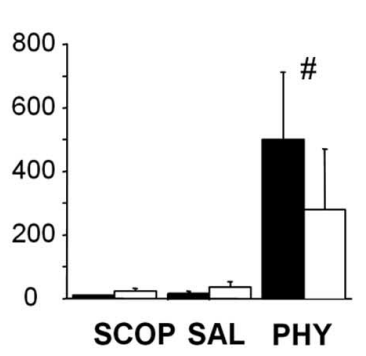

CA3

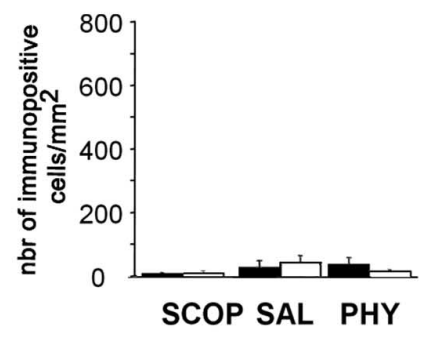

B

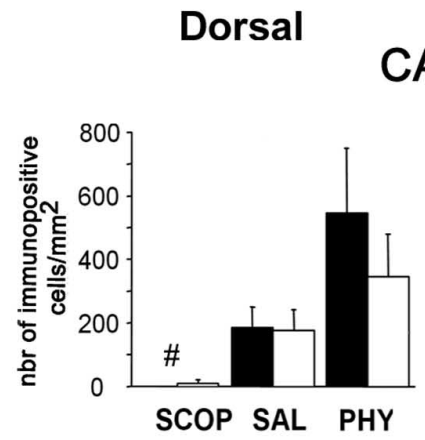

CA1

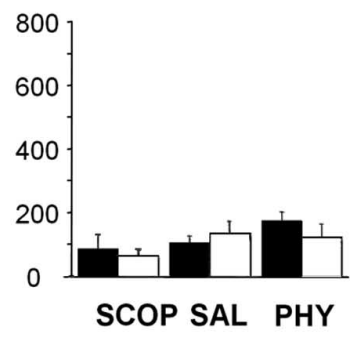

C
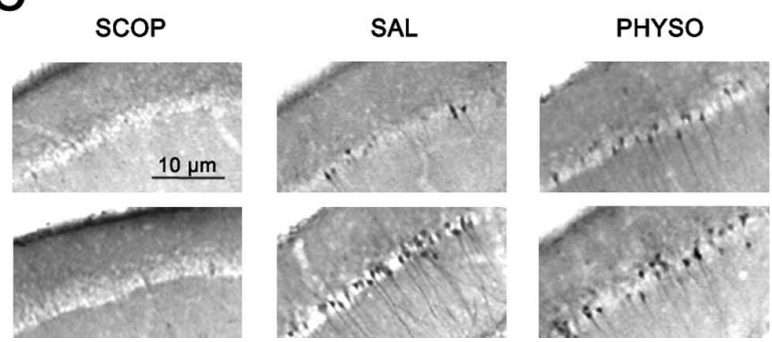

Figure 5. Effects of intrahippocampal infusions of $\operatorname{SAL}(n=10), \operatorname{SCOP}(n=10)$, and PHY $(n=10)$ on ERK1/2 phosphorylation in the hippocampus as a function of the conditioning procedure. $A$, Number of $p$-ERK1/2-immunopositive cells per square millimeter (mean \pm SEM) in SAL, PHY, and SCOP mice submitted to either a CS-US pairing or unpairing procedure in DG and $C A 3$ subregions of the dorsal (left) and ventral (right) hippocampus. $B$, Number of p-ERK1/ 2-immunopositive cells per square millimeter (mean \pm SEM) in SAL, PHY, and SCOP mice submitted to either a CS-US pairing or unpairing procedure in CA1 in the dorsal (left) and ventral (right) part of the hippocampus. C, Representative photomicrographs depicting p-ERK1/2 levels within the CA1 subregion of the ventral hippocampus in SAL, PHY, and SCOP mice submitted to either a CS-US pairing (top) or unpairing (bottom) procedure. * indicates conditioning effect (CS-US pairing vs unpairing); \# indicates pharmacological effect (SAL vs SCOP or SAL vs PHY) sostigmine increased ERK1/2 phosphorylation in these areas with a statistically significant effect in the ventral $\left(F_{(1,16)}=6.49, p=\right.$ $0.02)$ and dorsal $\left(F_{(1,15)}=9.09, p=0.008\right)$ DG. In addition, physostigmine produced an overall increase in p-ERK1/2 levels in CA1, with a statistically significant effect in the ventral CA1 in the pairing condition $\left(F_{(1,8)}=6.60, p=0.033\right)$. No change in $\mathrm{p}$-ERK1/2 expression was found in ventral CA3 whatever the type of infusions (no effect of infusions, $F_{(2,24)}=2.47, p>0.05$ ) nor in dorsal CA3 $\left(F_{(2,23)}=1.78, p>0.05\right)$.

Interestingly, in ventral (but not dorsal) CA1, saline-infused mice displayed significantly higher levels of $\mathrm{p}-\mathrm{ERK} 1 / 2$ when trained with the unpairing than mice trained with the pairing procedure (conditioning effect, $F_{(1,8)}=6.25, p=0.036$ ). This training-dependent effect was abolished in mice infused with either scopolamine $\left(F_{(1,8)}=0.086, p>0.05\right)$ or physostigmine $\left(F_{(1,8)}=0.19, p>0.05\right)$ (Fig. $\left.5 B, C\right)$. Whereas scopolamine infusions decreased p-ERK $1 / 2$ levels in the unpairing condition $\left(F_{(1,8)}=6.55, p=0.033\right)$, physostigmine infusions increased p-ERK1/2 levels in the pairing condition $\left(F_{(1,8)}=6.60, p=\right.$ 0.033 ). It follows that, whatever the training procedure, scopolamine infusions led to a low level of ERK1/2 activation indistinguishable from that observed in the saline-infused mice trained with the pairing procedure (all $F$ values $<0.03$, all $p$ values $>$ $0.05)$. In contrast, physostigmine infusions, again independent of training procedures, resulted in a level of ERK1/2 activation similar to saline-infused mice trained with the unpairing procedure (all $F$ values $<0.8$, all $p$ values $>0.05$ ).

ACh manipulation affects ERK1/2 activation in the amygdala Analysis of p-ERK1/2 was performed in the lateral and basolateral nuclei of the amygdala because these two nuclei have been shown to be critically required for the formation of the simple CS-US and context-US association (LeDoux, 2000; Nader et al., 2001; Yaniv et al., 2004; Calandreau et al., 2005).

First, in the LA, whatever the infusion group, p-ERK1/2 levels did not significantly differ as a function of the training procedure (conditioning, $F_{(1,24)}=3.8, p>0.05$; conditioning $\times$ treatment, $\left.F_{(2,24)}=1.03, p>0.05\right)$. Intrahippocampal infusions of scopolamine resulted in an overall decrease in p-ERK1/2 levels $\left(F_{(1,16)}=\right.$ $19.35, p=0.0004)$, whereas physostigmine had no overall effect on ERK1/2 activation $\left(F_{(1,16)}=2.49, p>0.05\right)$ (Fig. 6A).

Second, training-related but also infusion-related changes on p-ERK1/2 levels observed in the BLA very closely approximate the one described above in ventral hippocampus CA1. Namely, saline-infused animals trained with the pairing procedure displayed significantly lower $\mathrm{p}$-ERK $1 / 2$ levels in the BLA than salineinfused animals trained with the unpairing procedure $\left(F_{(1,8)}=\right.$ 9.22, $p=0.016)$. Moreover, scopolamine infusions decreased $\mathrm{p}$-ERK1/2 levels in mice trained with the unpairing procedure $\left(F_{(1,8)}=15.05, p=0.004\right)$, whereas physostigmine infusions increased p-ERK $1 / 2$ levels in mice trained with the pairing condition $\left(F_{(1,8)}=6.02, p=0.039\right)$. It follows that, in the BLA, as in CA1 subfield of the ventral hippocampus, regardless of training procedure, scopolamine-infused mice displayed similarly low levels of ERK1/2 activation as in the saline-infused mice trained with the pairing procedure. In contrast, physostigmine-infused mice did not differ from saline-infused mice trained with the unpairing procedure (all $F$ values $<2.3$, all $p$ values $>0.05$ ).

The patterns of $\mathrm{p}$-ERK1/2 levels in the LA and BLA observed here in saline-infused mice confirm our previous demonstration that the LA and BLA nuclei are differentially involved in fear conditioning as a function of the training procedure used (Calandreau et al., 2005). This training-related mapping of p-ERK1/2 in 
A
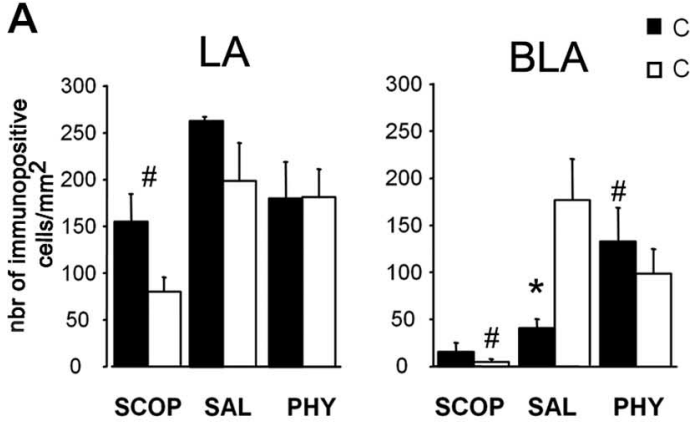

- cs-Us pairing B

c CS-US unpairing

C

SCOP

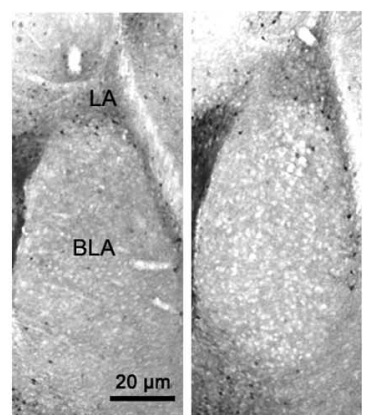

SAL

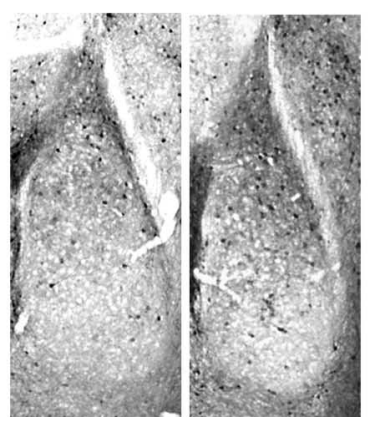

PHY

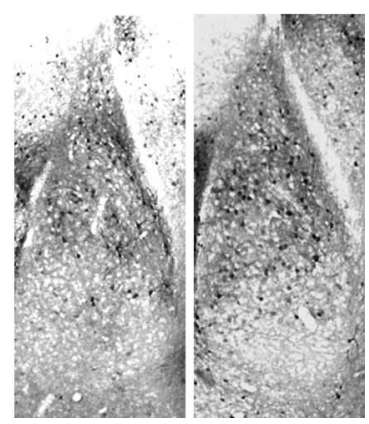

Figure 6. Effects of intrahippocampal infusions of SAL, SCOP, and PHY on ERK1/2 phosphorylation in the amygdala as a function of the conditioning procedure. $A$, Number of $p$-ERK1/2-immunopositive cells per square millimeter (mean $\pm S E M$ ) in SAL, SCOP, and PHY mice trained with either a CS-US pairing or unpairing conditioning procedure in the LA and BLA nuclei of the amygdala. $\boldsymbol{B}$, For each animal, the relative activity of each nucleus within the LA/BLA neural complex was calculated using the following ratio: (LA - BLA)/(LA + BLA). For each group, the mean \pm SEM ratio is presented. C, Representative photomicrographs depicting p-ERK1/2 levels in the LA and BLA nuclei of the amygdala in SAL, PHY, and SCOP mice submitted to either a CS-US pairing (left) or unpairing (right) procedure. * indicates conditioning effect (CS-US pairing vs unpairing); \# indicates pharmacological effect (SAL vs SCOP or SAL vs PHY)

the basolateral complex of the amygdala can be indexed by the LA/BLA ratio of p-ERK1/2 levels (legend to Fig. 6 B). Namely, when mice were trained with the pairing procedure, the LA displayed much more p-ERK1/2 levels than the BLA (ratio, 0.75 for a maximum of 1.0). In contrast, when mice were trained with the unpairing procedure, similar levels p-ERK1/2 activation were observed in both nuclei (ratio, 0.10 for a minimum of 0 ) (conditioning effect, $\left.F_{(1,8)}=21.50, p=0.001\right)$ (Fig. $4 B$ ). This effect of conditioning on the differential LA/BLA p-ERK1/2 activation was not observed in scopolamine- or physostigmine-infused mice. Indeed, regardless of the training procedure, scopolamine produced an LA/BLA p-ERK1/2 mapping similar to the one observed in controls (saline) trained with the pairing procedure (all ratio values tended to 1 ). In contrast, physostigmine produced a pattern of LA/BLA p-ERK1/2 activation close to that observed in controls trained with the unpairing procedure (all ratio values tended to 0 ) (Fig. 6B, C).

The above differences in ERK1/2 phosphorylation between the experimental groups cannot be accounted for by exposure to the tone CS, footshock US, or context per se, because all of these stimuli were presented equally in both the pairing and unpairing tone CS-US procedures. In addition, the present changes in p-ERK1/2 levels within the hippocampus and the amygdala are unlikely to be attributable to changes in ERK1/2 expression. Indeed, previous immunohistochemical data or Western blot analyses systematically showed no change in ERK1/2 expression whatever the brain region considered (including both the hip-

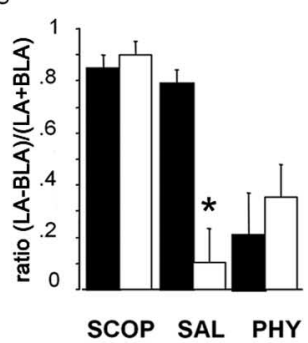

pocampus and the amygdala), the postconditioning delay, or the cholinergic manipulation used (Atkins et al., 1998; Rosenblum et al., 2000; Schafe et al., 2000; Berkeley et al., 2001).

\section{Discussion}

This study reveals that hippocampal cholinergic transmission regulates amygdala ERK1/2 activation and the adaptive balance between elemental and contextual fear conditioning. First, we show that a predominant context-US association (vs simple CS-US association) is associated with increased levels of ACh release in the hippocampus and with a specific pattern of ERK1/2 activation within the LA and BLA nuclei of the amygdala. Second, we provide evidence that changes in hippocampal cholinergic transmission make a causal contribution to both the selection of relevant emotional information and the associated pattern of ERK1/2 activation within the amygdala. Namely, intrahippocampal infusions of physostigmine suppressed conditioning to the predictive simple CS (pairing procedure) but promoted, in the same animals, conditioning to the context. Concomitantly, these infusions induced a pattern of LA/BLA ERK $1 / 2$ activation similar to that observed in controls trained with the CS-US unpairing procedure. Conversely, infusions of scopolamine mimicked both the behavioral (conditioning) and amygdalar (ERK1/2 activation) pattern of effects observed in controls trained with the CS-US pairing

procedure.

Hippocampal ACh contributes to the selection of relevant CS The first experiment shows that the magnitude of hippocampal ACh release is modulated by the conditioning procedure used. When the tone CS predicts the occurrence of the US in a precise (explicit) time-dependent manner (CS-US pairing; context in the background), the increment in ACh release is less than in a situation in which contextual stimuli are the primary stimuli to enter into association with the US (CS-US unpairing; context in the foreground). Hence, in agreement with the well documented role of the hippocampus in contextual conditioning (Selden et al., 1991; Holland and Bouton, 1999; LeDoux, 2000; Nail-Boucherie et al., 2000; Anagnostaras et al., 2001; Maren, 2001; Desmedt et al., 2003; Rudy et al., 2004), the magnitude of ACh release would reflect the degree to which the static contextual stimuli are processed by the hippocampus for their subsequent association with the US.

Our pharmacological experiments demonstrate that levels of hippocampal ACh are not only related to the magnitude of contextual conditioning but also play a deciding role in the selection of the best predictor (static contextual cues vs discrete tone stimulus) for the occurrence of the aversive US. First, enhancing hippocampal cholinergic transmission with physostigmine resulted in the selection of contextual stimuli (enhanced conditioning to the background context) instead of the tone cue (impaired con- 
ditioning to the tone explicitly paired with shock). Previous data have shown that interfering with hippocampal processes can disrupt elemental conditioning (Bast et al., 2003). Here, we show that augmenting the hippocampal cholinergic signal not only disrupts tone fear conditioning but also promotes contextual conditioning. Second, our study also reveals that, conversely, decreasing this cholinergic transmission with scopolamine resulted in the selection of the tone cue instead of foreground contextual cues, converting the nonpredictive tone CS (unpaired with shock) in a valid predictor for the US (conditioning to the tone). Moreover, this scopolamine-induced fear conditioning to the discrete tone is specific to the tone CS because such behavioral response cannot be explained by a generalized fear to any discrete stimulus that is not related to the aversive experience. Strikingly, this indicates that, under certain conditions, a discrete CS may enter into association with a US despite the absence of any explicit CS-US pairing. Actually, a similar switch from contextual to tone conditioning was observed previously in mice subjected to septal pharmacological manipulations aimed at reducing ACh release in the hippocampus (Desmedt et al., 1999). It has been suggested that decreasing hippocampal cholinergic transmission may prevent animals from forming a configural representation of the static contextual stimuli (Gale et al., 2001). As a consequence, animals would focus on the phasic tone CS, which would thus overshadow other cues because of its relatively high salience and capture most of the associative strength to the US.

Analysis of p-ERK1/2 supports a role for the hippocampal cholinergic transmission in the processing of contextual stimuli as foreground or background information. The pharmacologically induced increase (physostigmine) and decrease (scopolamine) in ERK1/2 activation within the hippocampus (CA1 and DG) parallel a prevalent contextual (context in foreground) and tone CS conditioning (context in background), respectively. Altogether, our results indicate that hippocampal cholinergic transmission regulates the hippocampal recruitment in fear conditioning, thereby contributing to the selection of the relevant information in emotional learning.

It must be noticed that, whereas the pharmacologically induced regulation of ERK1/2 was observed in both the dorsal and ventral hippocampus, alteration of the training-dependent ERK activation was restricted to the ventral hippocampus. Because this hippocampal sector is strongly connected to the amygdala, it may be preferentially required for emotional learning (Bannerman et al., 2004), and its pharmacologically induced modulation might well be associated with specific changes in the amygdalar function.

\section{Hippocampal ACh controls amygdalar function}

The present report also demonstrates that hippocampal cholinergic transmission influences learning-dependent mechanisms in the amygdala. First, control (saline-infused) mice trained with the pairing procedure displayed significantly higher $\mathrm{p}$-ERK1/2 levels in the LA than in the BLA. In contrast, after the unpairing procedure, similar levels of $\mathrm{p}$-ERK1/2 were observed in both nuclei. This observation is in agreement with previous studies (Nader at al., 2001; Yaniv et al., 2004; Calandreau et al., 2005). Specifically, using reversible inactivation, we showed previously that, when the discrete CS predicts the occurrence of the US, the LA is not only crucial for forming the CS-US association but also inhibits the BLA-mediated background context-US association. In contrast, when the CS does not predict the occurrence of the US, both nuclei contribute synergistically to the foreground context-US association. Consistent with that study (Calandreau et al., 2005), the present LA/BLA p-ERK1/2 mapping provides di- rect evidence that the engagement of each nucleus relative to the other one is dependent on whether a prevalent CS-US or contex$\mathrm{t}-\mathrm{US}$ association is selected.

Second, our study indicates that hippocampal cholinergic transmission constrains the training-dependent amygdalar pattern of ERK1/2 activation. Specifically, scopolamine produced an overall (regardless of the conditioning procedure) decrease of p-ERK1/2 levels in the LA and markedly reduced p-ERK1/2 levels in the BLA only in animals trained with the unpairing procedure. It follows that, regardless the conditioning procedure, the LA/ BLA pattern of $\mathrm{p}$-ERK $1 / 2$ in scopolamine-infused mice mimics that observed in controls trained with the pairing procedure (i.e., predominant tone conditioning, higher p-ERK1/2 levels in LA than in BLA). In contrast, physostigmine had no effect on LA p-ERK1/2 levels but increased p-ERK1/2 levels in the BLA only in animals trained with the pairing procedure. It follows that the LA/BLA pattern of $\mathrm{p}$-ERK1/2 in physostigmine-infused mice mimics that observed in controls trained with the unpairing procedure (i.e., predominant contextual conditioning, similar p-ERK1/2 levels in LA and BLA). These findings are thus in accordance with the current view supporting a role for ACh in regulating the relative contribution of different neural systems to learning (Marighetto et al., 1993; McIntyre et al., 2002; Gold, 2003; Parent and Baxter, 2004; Pych et al., 2005). It has been shown that a high level of ACh release in the hippocampus was associated with poor memory for the amygdala-dependent conditioned cue preference task (McIntyre et al., 2002) and, more generally, that the hippocampal-dependent processing of contextual information can interfere with the acquisition of this amygdala-dependent learning task (White and McDonald, 2002). Although in keeping with these previous findings, our present study further reveals that elevated levels of the hippocampal ACh not only favor the formation of a context-US association but also impede formation of an amygdala-based simple toneshock association. Conversely, reduced levels of the hippocampal ACh impede conditioning to the context but promote conditioning to the discrete tone.

Altogether, our findings indicate that the hippocampal cholinergic signal contributes to the tuning of the hippocampalamygdalar network and thereby subserves a selection process of the best predictor (simple CS or context) for the occurrence of an aversive event. Several data support this view. First, it is known that ACh increases the probability of NMDA receptor-mediated generation of long-term potentiation (LTP) (Markram and Segal, 1990), which is a major cellular model of learning and memory. Second, ERK1/2 activation has been shown to be required for hippocampal LTP (English and Sweatt, 1997) and regulated by ACh muscarinic receptors activity (Rosenblum et al., 2000). Third, we recently demonstrated that specific hippocampal patterns of ERK1/2 activation are associated with either a preferential tone or contextual fear conditioning (Trifilieff et al., 2006). Thus, hippocampal ACh signaling might constrain ERK1/2 activation within the hippocampal-amygdalar network, thereby subserving a preferential context-US or simple CS-US association.

\section{Concluding remarks}

Our study reveals that, depending on the predictive value of the CS for an aversive event, different levels of hippocampal ACh determine the relative engagement of the LA and BLA nuclei in bringing about the adaptive selection of either the simple CS or the context as a valid predictor. We are just beginning to understand the subtleties of the hippocampal-amygdalar interaction, 
and additional experiments will be required for exploring the neural connection and mechanisms responsible for this newly revealed functional influence. It must be emphasized that alterations in this hippocampal cholinergic control of the amygdala are sufficient to produce a subjective appraisal of emotionally laden stimuli that does not match their predictive values for aversive events. In particular, the intensification of emotional memory for an arousing simple stimulus and the concomitant weakening of context learning after intrahippocampal scopolamine infusions is reminiscent of the paradoxical coupling of memory intensification (for a simple trauma-related stimulus) and amnesia (for traumatic contextual cues) observed in human posttraumatic stress disorder (Elzinga and Bremner, 2002; Layton and Krikorian, 2002). Hence, such findings might highlight the neural dysfunction involved in pathological memories based on maladaptive processing of relevant emotional information.

\section{References}

Anagnostaras SG, Gale GD, Fanselow MS (2001) Hippocampus and contextual fear conditioning: recent controversies and advances. Hippocampus $11: 8-17$.

Atkins CM, Selcher JC, Petraitis JJ, Trzaskos JM, Sweatt JD (1998) The MAPK cascade is required for mammalian associative learning. Nat Neurosci 1:602-609.

Bannerman DM, Rawlins JN, McHugh SB, Deacon RM, Yee BK, Bast T, Zhang WN, Pothuizen HH, Feldon J (2004) Regional dissociations within the hippocampus: memory and anxiety. Neurosci Biobehav Rev 28:273-283.

Bast T, Zhang WN, Feldon J (2003) Dorsal hippocampus and classical fear conditioning to tone and context in rats: effects of local NMDA-receptor blockade and stimulation. Hippocampus 13:657-675.

Baxter MG, Holland PC, Gallagher M (1997) Disruption of decrements in conditioned stimulus processing by selective removal of hippocampal cholinergic input. J Neurosci 17:5230-5236.

Berkeley JL, Gomeza J, Wess J, Hamilton SE, Nathanson NM, Levey AI (2001) M1 muscarinic acetylcholine receptors activate extracellular signal-regulated kinase in CA1 pyramidal neurons in mouse hippocampal slices. Mol Cell Neurosci 18:512-524.

Blanchard RJ, Blanchard DC (1969) Crouching as a index of fear. J Comp Physiol Psychol 67:370-375.

Calandreau L, Desmedt A, Decorte L, Jaffard R (2005) A different recruitment of the lateral and basolateral amygdala promotes contextual or elemental conditioned association in Pavlovian fear conditioning. Learn Mem 12:383-388.

Chang Q, Savage LM, Gold PE (2006) Microdialysis measures of functional increases in ACh release in the hippocampus with and without inclusion of acetylcholinesterase inhibitors in the perfusate. J Neurochem 97:697-706.

Desmedt A, Garcia R, Jaffard R (1998) Differential modulation of changes in hippocampal-septal synaptic excitability by the amygdala as a function of either elemental or contextual fear conditioning in mice. J Neurosci 18:480-487.

Desmedt A, Garcia R, Jaffard R (1999) Vasopressin in the lateral septum promotes elemental conditioning to the detriment of contextual fear conditioning in mice. Eur J Neurosci 11:3913-3921.

Desmedt A, Marighetto A, Garcia R, Jaffard R (2003) The effects of ibotenic hippocampal lesions on discriminative fear conditioning to context in mice: impairment or facilitation depending on the associative value of a phasic explicit cue. Eur J Neurosci 17:1953-1963.

Elzinga BM, Bremner JD (2002) Are the neural substrates of memory the final common pathway in posttraumatic stress disorder (PTSD)? J Affect Disord 70:1-17.

English JD, Sweatt JD (1997) A requirement for the mitogen-activated protein kinase cascade in hippocampal long term potentiation. J Biol Chem 272:19103-19106.

Fendt M, Fanselow MS (1999) The neuroanatomical and neurochemical basis of conditioned fear. Neurosci Biobehav Rev 23:743-760.

Franklin KBJ, Paxinos G (1997) The mouse brain in stereotaxic coordinates. New York: Academic.

Gale G, Anagnostaras G, Fanselow M (2001) Cholinergic modulation of pavlovian fear conditioning: effects of intrahippocampal scopolamine in fusion. Hippocampus 11:371-376.

Gold PE (2003) Acetylcholine modulation of neural systems involved in learning and memory. Neurobiol Learn Mem 80:194-210.

Holland PC, Bouton ME (1999) Hippocampus and classical conditioning. Curr Opin Neurobiol 9:195-202.

Layton B, Krikorian R (2002) Memory mechanisms in posttraumatic stress disorder. J Neuropsychiatry Clin Neurosci 14:254-261.

LeDoux JE (2000) Emotion circuits in the brain. Annu Rev Neurosci 23:155-184.

Maren S (2001) Neurobiology of Pavlovian fear conditioning. Annu Rev Neurosci 24:897-931.

Marighetto A, Micheau J, Jaffard R (1993) Relationships between testinginduced alterations of hippocampal cholinergic activity and memory performance on two spatial tasks in mice. Behav Brain Res 56:133-144.

Markram H, Segal M (1990) Long-lasting facilitation of excitatory postsynaptic potentials in the rat hippocampus by acetylcholine. J Physiol (Lond) 427:381-393.

Marlin NA (1981) Contextual associations in trace conditioning. Anim Learn Behav 9:519-523.

McIntyre CK, Pal SN, Marriott LK, Gold PE (2002) Competition between memory systems: acetylcholine release in the hippocampus correlates negatively with good performance on an amygdala-dependent task. J Neurosci 22:1171-1176.

Moor E, Schirm E, Jacso J, Westerink BH (1998) Effects of neostigmine and atropine on basal and handling-induced acetylcholine output from ventral hippocampus. Neuroscience 82:819-825.

Nader K, Majidishad P, Amorapanth P, LeDoux JE (2001) Damage to the lateral and central, but not other, amygdaloid nuclei prevents the acquisition of auditory fear conditioning. Learn Mem 8:156-163.

Nail-Boucherie K, Dourmap N, Jaffard R, Costentin J (2000) Contextual fear conditioning is associated with an increase of acetylcholine release in the hippocampus of rat. Brain Res Cogn Brain Res 9:193-197.

Oschner KN, Bunge SA, Gross JJ, Gabrieli JDE (2002) Rethinking feelings: an fMRI study of the cognitive regulation of emotion. J Cogn Neurosci 14:1215-1229.

Parent MB, Baxter MG (2004) Septohippocampal acetylcholine: involved in but not necessary for learning and memory? Learn Mem 11:9-20.

Phelps EA (2004) Human emotion and memory: interactions of the amygdala and hippocampal complex. Curr Opin Neurobiol 14:198-202.

Phelps EA, O'Connor KJ, Gatenby JC, Gore JC, Grillon C, Davis M (2001) Activation of the left amygdala to a cognitive representation of fear. Nat Neurosci 4:437-441.

Phillips RG, LeDoux JE (1994) Lesions of the dorsal hippocampal formation interfere with background but not foreground contextual fear conditioning. Learn Mem 1:34-44.

Pych JC, Chang Q, Colon-Rivera C, Gold PE (2005) Acetylcholine release in hippocampus and striatum during testing on a rewarded spontaneous alternation task. Neurobiol Learn Mem 84:93-101.

Rescorla RA, Wagner AR (1972) A theory of Pavlovian conditioning: variations in the effectiveness of reinforcement and non reinforcement. In: Classical conditioning II (Black AH, Prokasy WF, eds), pp 64-99. New York: Appleton-Century-Croft.

Revest JM, Di Blasi F, Kitchener P, Rouge-Pont F, Desmedt A, Turiault M, Tronche F, Piazza PV (2005) The MAPK pathway and Egr-1 mediate stress-related behavioral effects of glucocorticoids. Nat Neurosci 8:664-672.

Rogers JL, Kesner RP (2004) Cholinergic modulation of the hippocampus during encoding and retrieval of tone/shock-induced fear conditioning. Learn Mem 11:102-107.

Rosenblum K, Futter M, Jones M, Hulme EC, Bliss TV (2000) ERKI/II regulation by the muscarinic acetylcholine receptors in neurons. J Neurosci 20:977-985.

Rudy JW, Huff NC, Matus-Amat P (2004) Understanding contextual fear conditioning: insights from a two-process model. Neurosci Biobehav Rev 28:675-685.

Schaefer SM, Jackson DC, Davidson RJ, Kimberg DY, Thompson-Schill SL (2002) Modulation of amygdalar activity by the conscious regulation of negative emotion. J Cogn Neurosci 14:913-921.

Schafe GE, Atkins CM, Swank MW, Bauer EP, Sweatt JD, LeDoux JE (2000) Activation of ERK/MAP kinase in the amygdala is required for 
memory consolidation of pavlovian fear conditioning. J Neurosci 20:8177-8187.

Selden NRW, Everitt BJ, Jarrard LE, Robbins TW (1991) Complementary roles for the amygdala and hippocampus in aversive conditioning to explicit and contextual cues. Neuroscience 42:335-350.

Shalin SC, Zirrgiebel U, Honsa KJ, Julien JP, Miller FD, Kaplan DR, Sweatt JD (2004) Neuronal MEK is important for normal fear conditioning in mice. J Neurosci Res 75:760-770.

Trifilieff P, Herry C, Vanhoutte P, Caboche J, Desmedt A, Riedel G, Mons N, Micheau J (2006) Foreground contextual fear memory consolidation requires two independent phases of hippocampal ERK/CREB activation. Learn Mem 13:349-358.

Wallenstein G, Wago D (2001) Intrahippocampal scopolamine infusions impairs both acquisition and consolidation of contextual fear conditioning. Neurobiol Learn Mem 75:245-252.

White NM, McDonald RJ (2002) Multiple parallel memory systems in the brain of the rat. Neurobiol Learn Mem 77:125-184.

Wilkinson LS, Humby T, Robbins TW, Everitt BJ (1995) Differential effects of forebrain 5-hydroxytryptamine depletions on Pavlovian aversive conditioning to discrete and contextual stimuli in the rat. Eur J Neurosci 7:2042-2052.

Winocur G, Rawlins JN, Gray JA (1987) The hippocampus and conditioning to contextual cues. Behav Neurosci 101:617-625.

Yaniv D, Desmedt A, Jaffard R, Richter-Levin G (2004) The amygdala and appraisal processes: stimulus and response complexity as an organizing factor. Brain Res Brain Res Rev 44:179-186. 